\title{
The influence of $\mathrm{TiO}_{2}$ nanoparticle incorporation on surface potential decay of corona-resistant polyimide nanocomposite films
}

\author{
Junwei Zha ${ }^{\mathrm{a}, \mathrm{b}}$, George Chen ${ }^{\mathrm{b}}$, Zhimin Dang ${ }^{\mathrm{a}, \mathrm{c}, *}$, Yi Yin ${ }^{\mathrm{c}}$ \\ ${ }^{a}$ Department of Polymer Science and Engineering, School of Chemistry and Biological Engineering, University of Science E Technology Beijing, Beijing 100083, China \\ ${ }^{\mathrm{b}}$ School of Electronics and Computer Science, University of Southampton, Southampton SO17 1BJ, United Kingdom \\ ' Shanghai Key Laboratory of Electric Insulation and Thermal Aging, Shanghai Jiao Tong University, Shanghai 200240, PR China
}

\section{A R T I C L E I N F O}

\section{Article history:}

Received 27 August 2010

Received in revised form

13 February 2011

Accepted 1 April 2011

Available online 24 April 2011

\section{Keywords:}

PI nanocomposite films

Corona charging

Surface potential decay

Surface potential cross-over

\begin{abstract}
A B S T R A C T
PI nanocomposite films containing surface modified nanoparticles by employing silane coupling agent were prepared using in-situ dispersion polymerization process. The surface potential decay measurements on films were investigated over the different negative corona-charged voltages and times in a controlled environment where temperature and relative humidity were kept at $21{ }^{\circ} \mathrm{C}$ and $45 \%$, respectively. There is a significant change in the surface potential decay characteristics after nano-fillers were introduced into polyimide. The surface potential decay pattern depends also on the amount of nano-fillers. The possible surface potential decay and corona resistance mechanisms responsible for the observed phenomena were discussed.
\end{abstract}

(c) 2011 Elsevier B.V. All rights reserved.

\section{Introduction}

Polymer nanocomposites have attracted wide interest as a method of enhancing polymer properties and extending their applications. Surface potential decay has been used widely as a tool to monitor charge transport and trapping characteristics of insulating materials. Since the early 1960 , there has been more interest in the surface potential decay of corona-charged polymeric materials in the open circuit configuration. The earlier surface potential decay research was on corona-charged polyethylene film which was given in some details by Ieda and co-workers [1]. One of the interesting phenomena in the observation of surface potential decay is the cross-over phenomenon, namely, the decay curves starting with different initial surface potentials cross each other during the decay process [2-5]. Over the years, many researchers have focused their studies on surface potential decay of coronacharged polymeric materials and various theories and models have been proposed to explain the cross-over phenomenon with various hypotheses such as field-dependant injection [6], charge trapping/detrapping process [7] and bulk polarization [8].

\footnotetext{
* Corresponding author. Department of Polymer Science and Engineering, School of Chemistry and Biological Engineering, University of Science \& Technology Beijing Beijing 100083, China.

E-mail addresses: zjw8226@hotmail.com (J. Zha), dangzm@ustb.edu.cn (Z. Dang).
}

Though many experimental results were presented so far, the physical mechanism of charge decay has not clearly been understood. Ieda et al. explained the decay curves only for low initial potentials using Ohm's law and predicted an exponentially surface potential decay $[1,9]$. Batra et al. assumed field-independent mobilities and demonstrated that the cross-over phenomenon is not associated with the finite depth of penetration [10]. Wintle et al. has developed theories that include field-independent mobilities of various forms as well as trapping [11].

Generally, due to clear characteristics of charge transporting and trapping in insulating materials under corona charging, the measurement of the surface potential decay has been proved to be a simple and useful technique. The technique involves with depositing charge on the surface of a polymer by means of a dc corona discharge and monitoring charge decay over a period of time using contactless probe. Many experiments on the charge transport in insulating polymers have been carried out using the surface potential decay method [12,13]. However, most of surface potential decay researches were on the single polymers such as polyethylene, epoxy, polypropylene and polyethylene terephthalate, little attention has been paid to surface potential decay in polymer nanocomposites [14-17].

In recent years, polyimide (PI) has received more and more attention in electrical and electronic industries due to its high thermal and chemical stability, good mechanical property and excellent electrical properties in a wide range of temperatures 
[18-21]. However, due to the rapid development of electrical engineering and electronic technology, it imposes more stringent requirements to the materials. The single tradition materials are facing more challenge, especially, they do not always withstand the damaging effects of corona, which can cause ionization and eventual breakdown of an insulation material or system when the voltage stress reaches to a critical level. To improve the insulating lifespan of high-voltage electrical equipment to resist the corona attack, there is strong interest in insulated polymer materials with good thermal stability and excellent corona resistance [22,23]. Due to the development of nano-technology and nano-materials, polymer nanocomposites are put forward as a kind of novel composite materials with improved insulating characteristics $[24,25]$. In this work, Polyimide/ $/ \mathrm{TiO}_{2}\left(\mathrm{PI} / \mathrm{TiO}_{2}\right)$ nanocomposite films containing surface modified nano- $\mathrm{TiO}_{2}$ particles by employing silane coupling agent were prepared using in-situ dispersion polymerization process. Surface potential decay characteristics of both pure $\mathrm{PI}$ film and $\mathrm{PI} / \mathrm{TiO}_{2}$ nanocomposite films (one-layer) were investigated over the different negative corona charging voltages and corona charging times using a needle-grid-ground electrode system under a controlled environment with temperature and relative humidity at $21{ }^{\circ} \mathrm{C}$ and $45 \%$, respectively. To investigate the influence of interface on surface potential decay, surface potential decays for four kinds of two-layer samples were also carried out. Results of the repeated experiments show that the potential decay is faster for higher initial potential and longer charging time. It has been found that there is a significant influence of nanoparticles on the surface potential decay characteristics of PI nanocomposite films. The surface potential decay curves depend also on the amount of nano- $\mathrm{TiO}_{2}$ particles. The schematic depiction of the possible charge transporting in different layer samples were presented.

\section{Experiment details}

\subsection{Fabrication of the polyimide nanocomposite films}

Both pure $\mathrm{PI}$ films and $\mathrm{PI} / \mathrm{TiO}_{2}$ nanocomposite films were prepared using in-situ dispersion polymerization process in the laboratory. Prior to use, the surface of the nano- $\mathrm{TiO}_{2}$ particles with a mean diameter of $\sim 50 \mathrm{~nm}$ was treated with $\gamma$-aminopropyltriethoxy silane (KH550) as a coupling agent in order to disperse the nano- $\mathrm{TiO}_{2}$ particles into PI matrix homogeneously. The $\mathrm{PI} / \mathrm{TiO}_{2}$ nanocomposite films were prepared by addition of the nano- $\mathrm{TiO}_{2}$ particles (from 5 to 15 wt.\%) into N, N-dimethylacetamide (DMAc) with the monomers of pyromellitic dianhydride (PMDA) and 4, 4'-oxy dianiline (ODA). Then the mixture was cast onto a cleaned glass plate and was held in the vacuum oven at room temperature to let the trapped air escape. After polyamid acid (PAA) was converted to PI by the thermal imidization, the PI/inorganic nanocomposite films were obtained. As a control experiment, the pure PI film was also prepared employing the same process. The thickness of all the films was close to $70 \mu \mathrm{m}$.

\subsection{Corona charging setup and potential decay measurement}

A schematic experimental setup in a controlled environment with temperature and relative humidity at $21^{\circ} \mathrm{C}$ and $45 \%$, respectively, is shown in Fig. 1a.

The samples were negatively charged on their free surface using a typical needle-grid-ground corona charging setup which consists of a high-voltage needle electrode, a wire mesh grid electrode and a rotatable earthed electrode. The needle electrode which connected to a negative dc high-voltage supply was situated above the grounded metallic plate. The grid electrode which was connected to a different negative dc high-voltage supply was situated between the needle electrode and the grounded plate. The distance between the needle and the mesh and between the mesh and the ground plate was $4.5 \mathrm{~cm}$ and $1.5 \mathrm{~cm}$, respectively. The area of the mesh and the sample was $150 \mathrm{~cm}^{2}$ and $25 \mathrm{~cm}^{2}$, respectively. In this way, a suitable electric field could be generated in the gap between the grid and the surface of the sample. After negative corona charging, the sample was quickly moved with the rotating system toward a compact JCI 140 static monitor to observe the surface potential decay. The duration of moving the rotating system is around $2 \mathrm{~s}$. However, the readings from the JCI 140 static monitor are not the direct values of the surface potential of the samples, a calibration should be made. A film with a thin gold coated is connected to a dc voltage. Readings from the JCI 140 static monitor are taken when varying the applied voltage. A liner relationship was obtained between the readings and the applied voltage as shown in Fig. 1b. According the equation inset in the Fig. 1b, the reading from the JCI 140 static monitor can be converted into the values of surface potential.

\section{Results and discussion}

Negative polarity was initially applied to corona charging electrode and the absolute value was used in the present paper when surface potential and time characteristics were plotted.

\subsection{Surface potential decay of one-layer films}

Influence of different corona charging voltages and charging times on surface potential decay characteristic of one-layer films were studied.
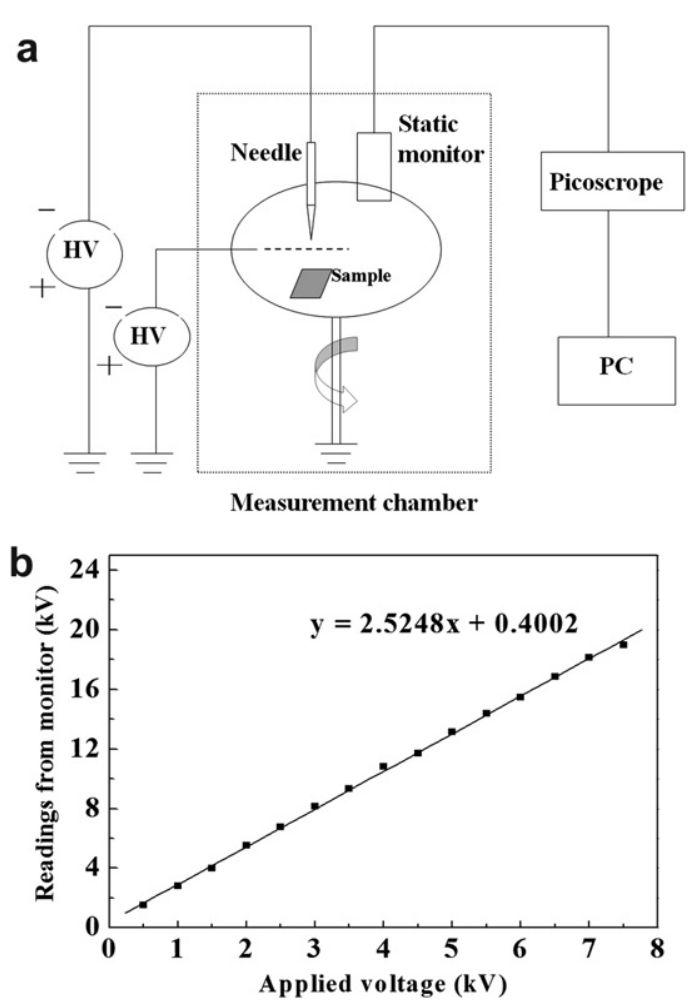

Fig. 1. (a) A schematic image of the experimental setup used for corona charging and surface potential measurement, (b) Calibration for the JCI 140 static monitor. 

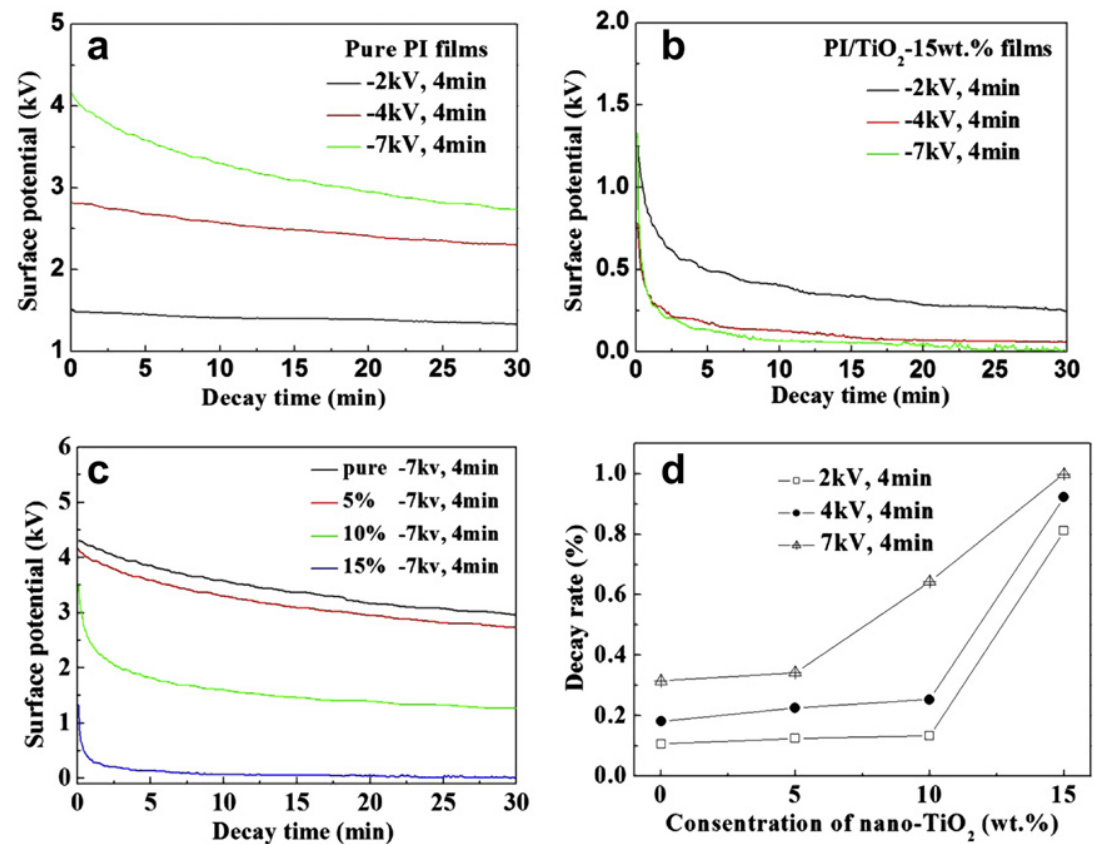

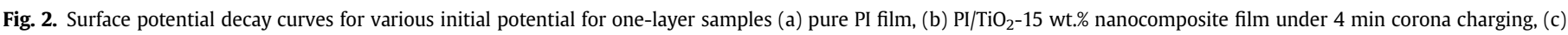

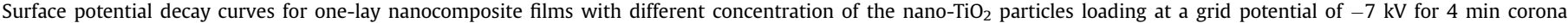
charging, (d) Decay rate curves for different charging levels, as a function of nano- $\mathrm{TiO}_{2}$ concentrations.

\subsubsection{Influence of different corona charging voltages}

The potential decay of corona-charged pure PI films with a thickness of $70 \mu \mathrm{m}$ under different negative charging voltages for $4 \mathrm{~min}$ is shown in Fig. 2a. It can be seen that decay curves starting with different initial surface potentials do not cross each other during the decay process. Surface potential decay curves show a monotonic decrease with the increasing decay time while the different rates of decay is observed, namely, the surface potential of the samples with initial high potential decays faster than that with lower surface potential. At low initial potential $(-2 \mathrm{kV})$, the surface potential is stable. It suggests that charges remain deeply trapped at the surface of the films. However, at high initial potential $(-4 \mathrm{kV},-7 \mathrm{kV})$, the surface potential decay is clearly observed with different rates of decay, and this trend becomes more obvious by raising the initial potential. This phenomenon has also been observed by other researchers $[1,2,14,15]$ and it can be concluded that the more deposited charges inject into the bulk under higher electric field.
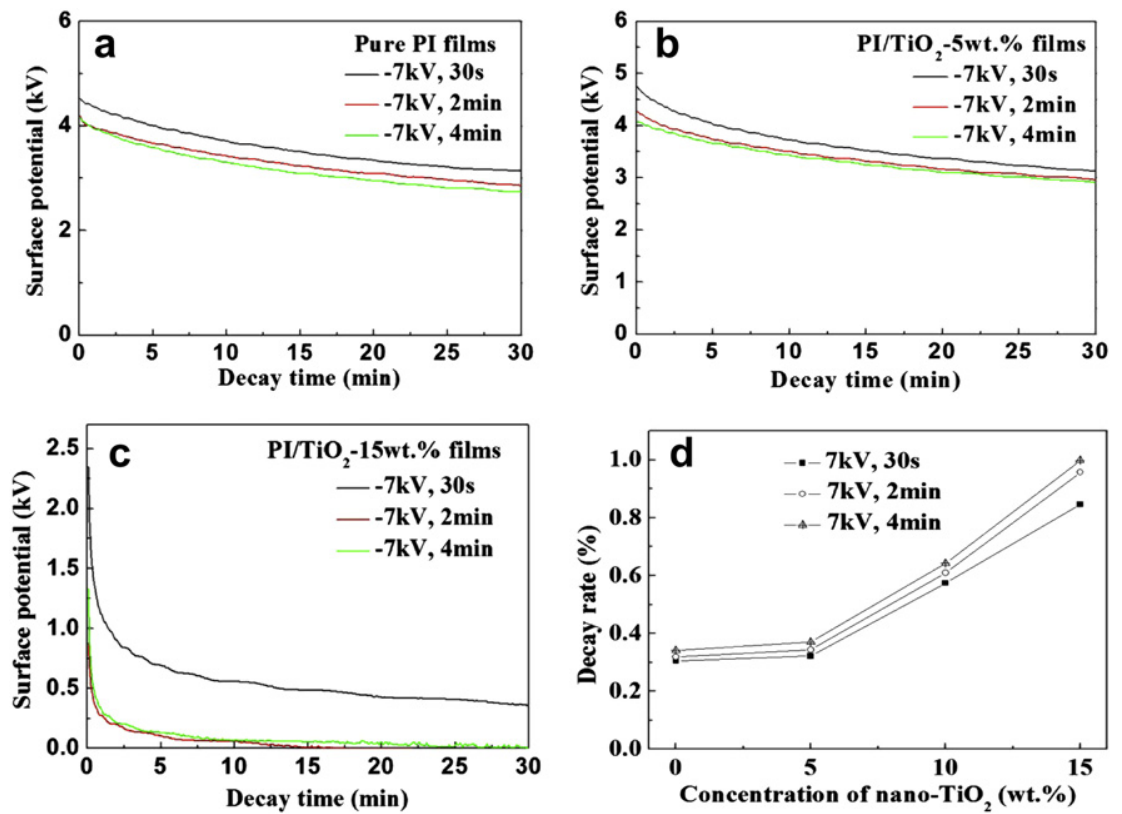

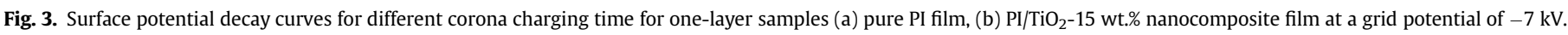
(c) Decay rate curves for different charging times, as a function of nano- $\mathrm{TiO}_{2}$ concentrations. 


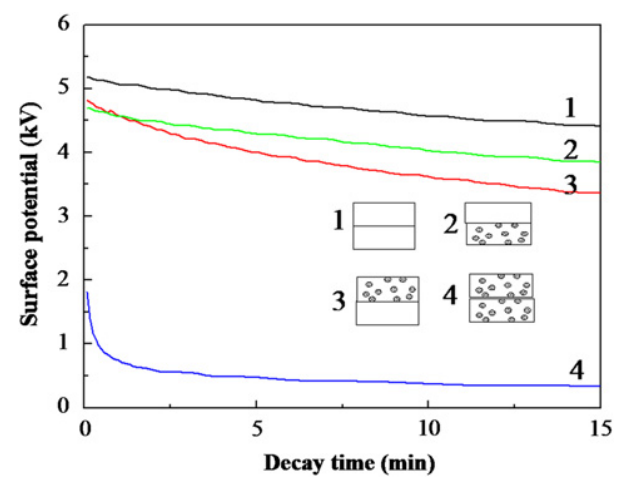

Fig. 4. Surface potential decay for two-layer samples at a grid potential of $-7 \mathrm{kV}$ for 4 min corona charging, where the number 1, 2, 3, 4 highlight the two-layer samples: pure-pure, pure-15 wt.\%, 15 wt.\%-pure and 15 wt.\%-15 wt.\%; $\%$ PI/TiO $2-15$ wt.\% film, $\square$ Pure PI film.

The similar surface potential decay phenomenon of $\mathrm{PI} / \mathrm{TiO}_{2}-$ $15 \mathrm{wt} . \%$ nanocomposite films with a thickness of $70 \mu \mathrm{m}$ is also shown in Fig. 2b. A fast initial decay at all charge deposit initial potentials was observed. Surface potential cross-over phenomenon has also been observed. However, cross-over occurs very early. The decay rate of $\mathrm{PI} / \mathrm{TiO}_{2}-15 \mathrm{wt}$.\% nanocomposite films decreases faster than that of pure PI films. This might be due to conductivity enhancement with incorporation of the $\mathrm{TiO}_{2}$ nanoparticles [26], resulting in easier and faster charge transport in the bulk. Fast charge decay has been also observed in space charge measurement of the same nanocomposite films [27].

In order to clearly understand the rate of potential decay, the decay curves of nanocomposite films with different concentration of the nano- $\mathrm{TiO}_{2}$ particles loading were compared, as shown in Fig. 2c. To give a better description and an effective evaluation on potential decay, the parameter $D$ is introduced as follows:

$D=\frac{U\left(t_{0}\right)-U(t)}{U\left(t_{0}\right)} \times 100 \%$

Where $U\left(t_{0}\right)$ and $U(t)$ are the potentials indicating the first decay point and the last decay point, respectively. $D$ is the decay rate of the films. Under the same charging conditions, decay rate curves for different charging levels, as a function of nano- $\mathrm{TiO}_{2}$ concentrations are presented in Fig. $2 \mathrm{~d}$.

The rate of decay becomes more faster with the concentration of the nano- $\mathrm{TiO}_{2}$ particles. When the concentration of the nano- $\mathrm{TiO}_{2}$ particles is higher (=15 wt.\%), the surface potential of the nanocomposite film decays very fast and approaches to zero at the end of the measurement, as shown in Fig. 2b. This behavior may be attributed to the fact that the partial injection of the deposited
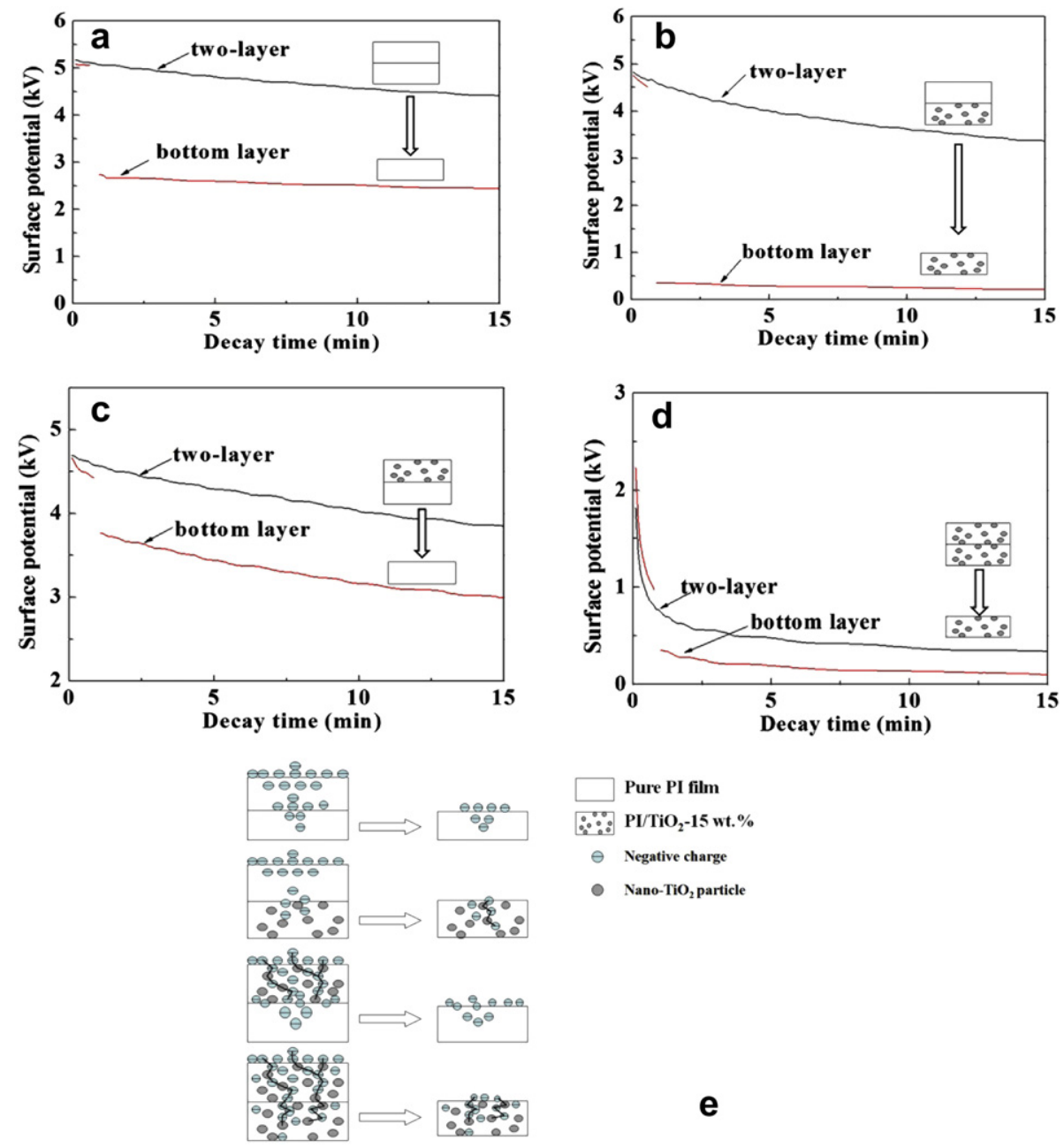

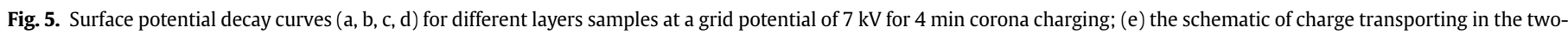
layer samples $\mathrm{PI} / \mathrm{TiO}_{2}-15$ wt.\% film, $\sqsubset$ Pure PI film. 
charges into the bulk depends on the level of concentration of the nano- $\mathrm{TiO}_{2}$ particles.

\subsubsection{Influence of different corona charging times}

In Fig. 3 the influence of charging times on the characteristic of the potential decay of pure $\mathrm{PI}$ film, $\mathrm{PI} / \mathrm{TiO}_{2}-5$ wt.\% nanocomposite film and $\mathrm{PI} / \mathrm{TiO}_{2}-15$ wt.\% nanocomposite film is shown. According to Equation (1), decay rate curves for different charging times, as a function of the nano- $\mathrm{TiO}_{2}$ concentrations are also presented in Fig. 3c. Several features should be noted. Firstly, the initial decay of surface potential is more rapid, and this is followed by a slower decay. Secondly, for the charging time from $30 \mathrm{~s}$ to $4 \mathrm{~min}$, the first recorded value of the surface potential of the $\mathrm{PI} / \mathrm{TiO}_{2}-15 \mathrm{wt} . \%$ nanocomposite film is well below than that of the $\mathrm{PI} / \mathrm{TiO}_{2}-5 \mathrm{wt} . \%$ nanocomposite film. There are two possible reasons (i) the surface potential never reaches to the grid electrode potential; (ii) there is a rapid decay process taken place. From Fig. 3, it seems that the latter is responsible for the lower initial observed surface potential. Of course, the feature is closely associated with the material composition. When the charging time is increased from $30 \mathrm{~s}$ to $4 \mathrm{~min}$, there is very weak impact on surface potential decay of pure PI films, as shown in Fig. 3a. However, the influence of corona charging duration on surface potential decay of $\mathrm{PI} / \mathrm{TiO}_{2}-15$ wt\% nanocomposite films is remarkable, as shown in Fig. 3b. It indicates that the charges injected from the needle electrode could be easily held in the pure PI film.

\subsection{Surface potential decay of two-layer films}

Considering all surface potential decay curves of nanocomposite films change little after $15 \mathrm{~min}$, the decay duration was set as $15 \mathrm{~min}$ for all other decay measurements. Surface potential decay of four kinds of two-layer samples $(70 \mu \mathrm{m}+70 \mu \mathrm{m})$ was carried out and the results are shown in Fig. 4. All samples were subjected to a negative corona charging at a grid potential of $-7 \mathrm{kV}$ for $4 \mathrm{~min}$. The surface potential was observed for $15 \mathrm{~min}$ after the corona charging supply was switched off. The decay rate of pure-pure sample is slower than that of $15 \mathrm{wt} . \%-15 \mathrm{wt} . \%$ sample and the cross-over phenomenon is still observed. This may be due to the different abilities of charges transporting in the bulk of different films, while the thickness and interface should also play an important role [4,5].

\subsection{Mechanism of charge transporting during the surface potential decay}

In this section, all samples were subjected to a negative corona charging at a grid potential of $-7 \mathrm{kV}$ for $4 \mathrm{~min}$. The surface potential was observed for $15 \mathrm{~min}$ after the corona charging supply was switched off.

In order to understand the charge movement of the multi-layer films, two measurements were carried out for comparison. 1) The potential decay of two-layer films was continuously monitored for $15 \mathrm{~min}$. 2) The potential of two-layer films was firstly monitored for $1 \mathrm{~min}$, and then the bottom layer was continuously monitored after the top layer was carefully removed. The time required to tear off the top layer and transfer the bottom layer for potential decay measurement is around $10 \mathrm{~s}$. When the top layer was removed, the surface potential decay of the bottom layer could still be observed as shown in Fig. 5.

The interface between the two layers and the ability of charge transporting may have a great effect on the surface potential decay. The possible mechanism of charge transporting in the four different two-lay samples is fully presented in Fig. 5e. The charges will accumulate on the surface of the top layer when the negative voltage applied with the duration of $4 \mathrm{~min}$. For pure PI film, a few charges are transferred into the bulk of top layer and then some charges are transferred into the bulk of bottom layer during the process of corona charging. These charges easily be hold in the bulk of pure PI films, so the potential decay curves of two-layer and the bottom layer are similar but with different initial potential, as shown in Fig. 5a and e. Compared with Fig. 5a, the rapid rate of decay is apparently observed in Fig. $5 \mathrm{~d}$ due to both the top layer and the bottom layer are $\mathrm{PI} / \mathrm{TiO}_{2}-15 \mathrm{wt} . \%$ nanocomposite films. The bulk injection become more easily in the $\mathrm{PI} / \mathrm{TiO}_{2}-15 \mathrm{wt} . \%$ nanocomposite film since the nano- $\mathrm{TiO}_{2}$ particles can build up a conductive network in the nanocomposite film [28]. The charges injected into the bulk could hardly be hold and the surface potential of the $\mathrm{PI} / \mathrm{TiO}_{2}-15 \mathrm{wt} . \%$ nanocomposite film decays very fast and approaches to zero when the top layer is carefully torn off, as shown in Fig. 5b,d and e.

\subsection{Corona resistance of PI nanocomposite films}

With the results of surface potential decay above, it can be assumed that the ability of transporting the electrons in the pure PI film is weaker than that in the $\mathrm{PI} / \mathrm{TiO}_{2}$ nanocomposite films. The presence of nano- $\mathrm{TiO}_{2}$ particles has remarkably modified charge transportation. In our previous work, the improved coronaresistant characteristic in the $\mathrm{PI} / \mathrm{TiO}_{2}$ nanocomposite films were analyzed employing the model of the effect of nano- $\mathrm{TiO}_{2}$ particles on the degradation endurance of the $\mathrm{PI} / \mathrm{TiO}_{2}$ nanocomposite films, which was relative to the corona aging lifespan and subsequent breakdown strength [29]. Based on the present results, an alternative explanation is proposed as schematically shown in Fig. 6.

For the needle electrode at negative polarity, electrons are injected into the bulk of the films and would be move through the material under the electric field. These electrons in the pure PI film play two important roles. One role is that a few electrons would be trapped into deep or shallow traps by scattering. The second role is that most electrons obtain the energy due to non-radiative transition [30], and then it can be transferred to another electron and make it become a hot electron, as shown in Fig. 6a. The hot electron can have sufficient energy to break the polymer chains. The energy

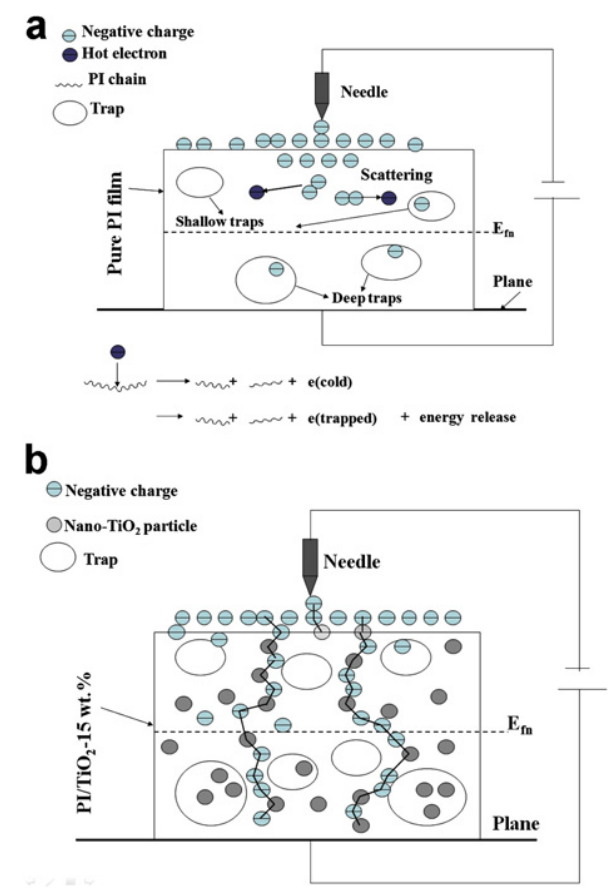

Fig. 6. Schematic for the influence of the nano- $\mathrm{TiO}_{2}$ particles on corona resistance of the films. 
will be released after dissociating a molecule into free radicals and transferred to a third electron and make it become another hot electron. The process is repeating in the bulk of the film, leading to a process of aging.

However, when the nano- $\mathrm{TiO}_{2}$ particles dispersed into PI matrix, there are also two possible mechanisms in the films, as shown in Fig. 6b. Firstly, electrons would be easily transferred under the electric field due to the formation of the conductive network by the nano- $-\mathrm{TiO}_{2}$ particles in the bulk. The nano- $\mathrm{TiO}_{2}$ particles would possibly hold free volume and the large traps to decrease the amount of free volume. Secondly, it takes an effect on the dissipation of the accumulated electric energy and the probability for an electron becoming a hot electron is much lower. And thus avoids the direct collision of the chains by the charged particles and decreasing the chance of their initiation of dielectric breakdown. So the corona aging lifespan of the nanocomposite films also increased with incorporation of the nano- $\mathrm{TiO}_{2}$ particles.

\section{Conclusion}

In summary, polyimide nanocomposite films loaded with different concentration of the nano- $\mathrm{TiO}_{2}$ particles were fabricated using in-situ dispersive polymerization. The surface potential decays in these nanocomposite films (both one-layer and twolayer) have been investigated by using the corona charging setup. The main conclusions are as follows.

The surface potential of the samples (both one-layer and twolayer) with initial high potential decays faster than that with lower surface potential. There is a significant influence of nanoparticles on the surface potential decay characteristics of PI nanocomposite films. The surface potential decay curves depend also on the amount of nano- $\mathrm{TiO}_{2}$ particles.

The incorporation of the nano- $\mathrm{TiO}_{2}$ particles can build up a conductive network in the nanocomposite film, which increases the chance of charge transporting in the bulk. The corona resistance of the nanocomposite films could be improved with the nano- $\mathrm{TiO}_{2}$ particles loading.

\section{References}

[1] M. Ieda, G. Sawa, U. Shinohara, A decay process of surface electric charges across polyethylene film, Jpn. J. Appl. Phys. 6 (1967) 793-794.

[2] E.A. Baum, T.J. Lewis, R. Toomer, Decay of electrical charge on polyethylene film, J. Phys. D: Appl. Phys. 10 (1977) 487-497.

[3] J.A. Giacometti, O.N. Oliveira, Corona charging of polymers, IEEE Trans. Electr. Insul. 27 (1992) 924-943.

[4] Z. Xu, L. Zhang, G. Chen, Decay of electric charge on corona charged polyethylene, J. Phys. D: Appl. Phys. 40 (2007) 7085-7089.

[5] G. Chen, A new model for surface potential decay of corona-charged polymers, J. Phys. D: Appl. Phys. 43 (2010) 1-7.

[6] T.J. Sonnonstein, M.M. Perlman, Surface potential decay in insulators with field dependent mobility and injection efficiency, J. Appl. Phys. 46 (1975) 3975-3981.
[7] H.J. Wintle, Surface charge decay in insulators with non-constant mobility and with deep trapping. J. Appl. Phys. 43 (1972) 2927-2930.

[8] V. Pouilles, T. Lebey, P. Castelanm, Determination of the very low-frequency characteristics of dielectric materials: a surface potential approach, J. Appl. Phys. 79 (1996) 8620-8628.

[9] M. Ieda, G. Sawa, R. Takeuchi, Decay processes of different kinds of surface electric charges across polyethylene film, Jpn. J. Appl. Phys. 8 (1969) 809.

[10] I.P. Batra, K.K. Kanazawa, On the "cross-over" effect in surface potential decay, Jpn. J. Appl. Phys. 11 (1972) 267-268.

[11] H.J. Wintle, Decay of surface electric charge in insulators, Jpn. J. Appl. Phys. 10 (1971) 659-660.

[12] T. Mizutani, T. Oomura, M. Ieda, Surface potential decay in polyethylene, Jpn. J. Appl. Phys. 20 (1989) 855-859.

[13] A. Aragoneses, M. Mudarra, J. Belana, J.A. Diego, Study of dispersive mobility in polyimide by surface voltage decay measurements, Polym 49 (2008) 2440-2443.

[14] G. Chen, Z. Xu, L.W. Zhang, Measurement of the surface potential decay of corona-charged polymer films using the pulsed electroacoustic method, J. Meas. Sci. Technol. 18 (2007) 1453-1458.

[15] S. Sahli, A. Bellel, Z. Ziari, A. Kahlouche, Y. Segui, Measure and analysis of potential decay in polypropylene films after negative corona charge deposition, J. Electrostat. 57 (2003) 169-181.

[16] P. Molinié, M. Goldman, J. Gattelet, Surface potential decay on corona-charged epoxy samples due to polarization processes, J. Phys. D: Appl. Phys. 28 (1995) 1601-1610.

[17] L. Herous, M. Nemamcha, M. Remadnia, L. Dascalescu, Factors that influence the surface potential decay on a thin film of polyethylene terephthalate (PET) J. Electrostat. 67 (2009) 198-202.

[18] T. Liang, Y. Makita, S. Kimura, Effect of film thickness on the electrical properties of polyimide thin films, Polym 42 (2001) 4867-4872.

[19] L.R. Zhou, G.N. Wu, B. Gao, K. Zhou, J. Liu, K.J. Cao, L.J. Zhou, Study on charge transport mechanism and space charge characteristics of polyimide films, IEEE Trans. Dielectr. Electr. Insul. 16 (2009) 1143-1149.

[20] X. Jiang, Y. Bin, M. Matsuo, Electrical and mechanical properties of polyimidecarbon nanotubes composites fabricated by in situ polymerization, Polym 46 (2005) 7418-7424.

[21] T. Agag, T. Koga, T. Takeich, Studies on thermal and mechanical properties of polyimide-clay nanocomposites, Polym 42 (2001) 3399-3408.

[22] P. Zhang, W. Zhang, Y. Liu, Y. Fan, Q. Lei. Study on corona-resistance of polyimide-nano inorganic composites. In: Proc. Seventh Intern. Conf. Prope. Appli. Dielec. Mater., 2003, pp. 1138-1141.

[23] Y. Zhu, M. Otsubo, C. Honda, Degradation of polymeric materials exposed to corona discharges, Polym. Test 25 (2006) 313-317.

[24] T. Tanaka, M. Kozako, N. Fuse, Y. Ohki, Proposal of a multi-core model for polymer nanocomposite dielectrics, IEEE Trans. Dielectr. Electr. Insul. 12 (2005) 669-681.

[25] T. Tanaka, G.C. Montanari, R. Mülhaupt, Polymer nanocomposites as dielectrics and electrical insulation-perspectives for processing technologies, material characterization and future applications, IEEE Trans. Dielectr. Electr. Insul. 11 (2004) 763-784.

[26] J.W. Zha, Z.M. Dang, H.T. Song, Y. Yin, G. Chen, Dielectric properties and effect of electrical aging on space charge accumulation in polyimide $/ \mathrm{TiO}_{2}$ nanocomposite films, J. Appl. Phys. 108 (2010) 094113.

[27] J. Zha, Z. Dang, G. Chen, Space charge dynamics in polyimide based nanocomposites. In: IEEE Intern. Sympo. Electr. Insul. San Diego, 2010, ISSN:1089-084X.

[28] H.P. Xu, Z.M. Dang, S.H. Yao, M. Jiang, Exploration of unusual electrical properties in carbon black/binary-polymer nanocomposites, Appl. Phys. Lett. 90 (2007) $1529121-3$.

[29] J.W. Zha, H.T. Song, Z.M. Dang, C.Y. Shi, J. Bai, Mechanism analysis of improved corona-resistant characteristic in polyimide $/ \mathrm{TiO}_{2}$ nanohybrid films, Appl. Phys. Lett. 93 (2008) 192911 1-3.

[30] C.K. Kwan, New theory of electrical discharge and breakdown in low-mobility condensed insulators, J. Appl. Phys. 55 (1984) 752-755. 